Research article

Open Access

\title{
Proton-pump inhibitors are associated with a reduced risk for bleeding and perforated gastroduodenal ulcers attributable to non-steroidal anti-inflammatory drugs: a nested case-control study
}

\author{
Harald E Vonkeman ${ }^{1}$, Robert W Fernandes ${ }^{2}$, Job van der Palen ${ }^{3}$, Eric N van Roon ${ }^{4}$ and \\ Mart AFJ van de Laar $^{1}$
}

\author{
1Department of Rheumatology and Clinical Immunology, Medisch Spectrum Twente Hospital and University of Twente, Ariensplein 1, 7500 KA, \\ Enschede, The Netherlands \\ 2Stroinkslanden Pharmacy, Veldhoflanden 90, 7542 LX, Enschede, The Netherlands \\ ${ }^{3}$ Department of Clinical Epidemiology and Statistics, Medisch Spectrum Twente Hospital, Haaksbergerstraat 55, 7500 KA, Enschede, The \\ Netherlands \\ ${ }^{4}$ Department of Clinical Pharmacy and Clinical Pharmacology, Medisch Centrum Leeuwarden, Henri Dunantweg 2, 8934 AD, Leeuwarden, The \\ Netherlands \\ Corresponding author: Harald E Vonkeman, h.vonkeman@ziekenhuis-mst.nl
}

Received: 11 Feb 2007 Revisions requested: 16 Apr 2007 Revisions received: 28 Apr 2007 Accepted: 23 May 2007 Published: 23 May 2007

Arthritis Research \& Therapy 2007, 9:R52 (doi:10.1186/ar2207)

This article is online at: http://arthritis-research.com/content/9/3/R52

(c) 2007 Vonkeman et al.; licensee BioMed Central Ltd.

This is an open access article distributed under the terms of the Creative Commons Attribution License (http://creativecommons.org/licenses/by/2.0), which permits unrestricted use, distribution, and reproduction in any medium, provided the original work is properly cited.

\begin{abstract}
Treatment with non-steroidal anti-inflammatory drugs (NSAIDs) is hampered by gastrointestinal ulcer complications, such as ulcer bleeding and perforation. The efficacy of proton-pump inhibitors in the primary prevention of ulcer complications arising from the use of NSAIDs remains unproven. Selective cyclooxygenase-2 (COX-2) inhibitors reduce the risk for ulcer complications, but not completely in high-risk patients. This study determines which patients are especially at risk for NSAID ulcer complications and investigates the effectiveness of different preventive strategies in daily clinical practice. With the use of a nested case-control design, a large cohort of NSAID users was followed for 26 months. Cases were patients with NSAID ulcer complications necessitating hospitalisation; matched controls were selected from the remaining cohort of NSAID users who did not have NSAID ulcer complications.
\end{abstract}

During the observational period, 104 incident cases were identified from a cohort of 51,903 NSAID users with 10,402 patient years of NSAID exposure (incidence 1\% per year of NSAID use, age at diagnosis $70.4 \pm 16.7$ years (mean \pm SD), $55.8 \%$ women), and 284 matched controls. Cases were characterised by serious, especially cardiovascular, comorbidity. In-hospital mortality associated with NSAID ulcer complications was $10.6 \%$ (incidence 21.2 per 100,000 NSAID users). Concomitant proton-pump inhibitors (but not selective COX-2 inhibitors) were associated with a reduced risk for NSAID ulcer complications (the adjusted odds ratio $0.33 ; 95 \%$ confidence interval 0.17 to $0.67 ; p=0.002$ ). Especially at risk for NSAID ulcer complications are elderly patients with cardiovascular co-morbidity. Proton-pump inhibitors are associated with a reduced risk for NSAID ulcer complications.

\section{Introduction}

Treatment with non-steroidal anti-inflammatory drugs (NSAIDs) is known to be complicated by gastrointestinal toxicity. NSAIDs impair prostaglandin-dependent gastric mucosal protective mechanisms. When these defences have been breached, a second wave of injury caused by luminal gastric acid may facilitate deeper ulceration [1]. Prevention of gas- troduodenal ulcers attributable to the use of NSAIDs may target the inhibition of gastric acid secretion with histamine-2 receptor antagonists (H2RAs) or proton-pump inhibitors (PPIs). Alternatively, locally depleted endogenous cytoprotective prostaglandins may be replaced by the administration of prostaglandin $E_{1}$ analogues, such as misoprostol. Several studies have evaluated and compared these strategies [2].

$\mathrm{COX}=$ cyclooxygenase; $\mathrm{H} 2 \mathrm{RAs}=$ histamine-2 receptor antagonists; INR = international normalized ratio; NSAIDs = non-steroidal anti-inflammatory drugs; $\mathrm{PPls}=$ proton-pump inhibitors. 
High-dose misoprostol is effective in the primary prevention of endoscopic NSAID ulcers and also NSAID ulcer complications, such as bleeding and perforation, but is often poorly tolerated because of diarrhoea and abdominal discomfort [3]. Elevation of the intragastric $\mathrm{pH}$ by PPls and high-dose $\mathrm{H} 2 \mathrm{RAs}$ reduces the risk of endoscopic NSAID ulcers [2]. In direct comparison, PPIs show an efficacy comparable to that of misoprostol, but they are better tolerated [4]. Furthermore, PPIs are more effective in the prevention of NSAID ulcers than lowdose H2RAs [5]. However, the efficacy of PPIs and H2RAs in the primary prevention of clinically relevant endpoints, such as bleeding and perforated NSAID ulcers, remains unproven.

The discovery of the isoenzymes cyclooxygenase (COX)-1 and COX-2 made it possible to develop highly selective COX2 inhibitors [6]. The hypothesis is that COX-1 is expressed constitutively and regulates normal physiology, such as the maintenance of gastric mucosal integrity. Conversely, COX-2 is expressed selectively after exposure to inflammatory mediators or trauma, and has a role in inflammation and pain [7]. In randomised controlled clinical trials, selective COX-2 inhibitors have demonstrated a decreased risk for NSAID ulcers and also ulcer complications [8-11]. Furthermore, in elderly patients with a recent history of bleeding NSAID ulcers, secondary prevention (preventing recurrent bleeding) with a selective COX-2 inhibitor seems comparable to combining a non-selective NSAID with a PPI, although in that study the number of cases was small and neither strategy provided adequate protection [12].

Because of their relatively low incidence, severe gastrointestinal ulcer complications such as bleeding and perforated ulcers can be evaluated most effectively in large observational studies [13]. Randomised controlled clinical trials are designed to evaluate the efficacy of a certain strategy, and despite including thousands of patients they may fail to detect infrequent or long-term complications or side effects. Furthermore, rigorous inclusion and exclusion criteria are maintained, and those at high risk for drug side effects or complications are usually excluded. Conversely, in daily clinical practice, it is especially at-risk patients who are likely to be treated with these new strategies under the assumption of safe, evidencebased pharmacotherapy. Although observational studies are subject to possible bias, they best reflect daily clinical practice and are well suited to study infrequent and long-term complications and side effects. Therefore, to determine the characteristics of patients who are especially at risk for serious NSAID ulcer complications and to compare the effectiveness of different preventive strategies in daily clinical practice, we conducted a large nested case-control study.

\section{Materials and methods}

This nested case-control study was performed within the government-initiated healthcare region of the city of Enschede in The Netherlands. On 31 December 2003 the population con- sisted of 152,989 persons living in a well-defined geographically isolated area largely bordering on Germany. All in-patient healthcare is provided by a single teaching hospital, supplied with all diagnostic and therapeutic facilities. All drug prescriptions are registered in electronic prescription records of 14 local pharmacies. Most drugs, including NSAIDs, are provided by the patient's own pharmacy, directly reimbursed by the healthcare system. A cohort of NSAID users can be identified continuously from the electronic prescription records.

Serious NSAID ulcer complications were defined as ulcerations of the stomach or proximal duodenum causing perforation, obstruction or bleeding that occurred during the use of NSAIDs, necessitating hospitalisation of the patient.

\section{Selection of cases}

During a prospective 26-month observational period (November 2001 to December 2003), we identified all consecutive NSAID users who were hospitalised with serious NSAID ulcer complications. Most patients were identified during endoscopy or abdominal surgery. A few patients were identified on the basis of a clinical presentation of upper gastrointestinal bleeding alone, with haematemesis or melaena, if no further diagnostic procedure was performed because of co-morbidity or advanced age. In some of these patients the diagnosis was confirmed during autopsy. Patients were included in the study if they used NSAIDs (including selective COX-2 inhibitors) at the time of diagnosis of a gastroduodenal ulcer. Aspirin in high dosage (more than $100 \mathrm{mg}$ daily) was considered to be a NSAID. As soon as possible after the diagnosis, patients were given a questionnaire on their sociodemographic characteristics, actual and recent medication, co-morbidity and medical history. The questionnaire contained specific items on the use of NSAIDs, aspirin, anticoagulants, gastroprotective drugs, and steroids, and also on the history of gastroduodenal events. For verification of the questionnaires, we reviewed the medical charts of all cases, as well as reports on endoscopy, surgery and pathology. Medication use before and during hospitalisation, as reported by the patient, was verified by reviewing prescription registrations provided by the in-hospital and community-based pharmacies. Patients were interviewed by one of the authors (HV) if ambiguities were encountered in the questionnaires or during verification.

Patients were excluded if they reported not having used NSAIDs, if endoscopy, surgery or autopsy did not reveal gastroduodenal ulcers, if ambiguities remained despite interviewing the patient, if a malignancy of the stomach was diagnosed or if another reason for upper intestinal bleeding (such as esophagogastric varices, arteriovenous malformations, diffuse gastritis or Mallory-Weiss tears) was diagnosed.

\section{Selection of controls}

Matched controls were selected from the remaining cohort of NSAID users. For selecting controls, index dates were defined 
as the day on which an NSAID ulcer was diagnosed in each of the cases. Controls were frequency-matched on sex and age, and had to be using NSAIDs (including selective COX-2 inhibitors) on the index date. Selected controls were asked to complete the same questionnaire as the cases. Medication use as reported by the controls was verified by reviewing prescription databases. Controls were interviewed if ambiguities were encountered in the questionnaires or during verification. All non-responders were sent a second identical questionnaire. Finally, a random sample of non-responders was telephoned to detect bias in non-responding.

\section{Statistical analysis}

In univariate analyses, potential confounding continuous variables were analysed with Student's $t$-test and nominal data were analysed with Pearson $\chi^{2}$ tests or Fisher's exact tests for small numbers. Multivariate analyses were performed by using logistic regression with NSAID ulcers as the dependent variable. A full model consisting of all significant and other likely causational variables was reduced stepwise to a parsimonious model. All $p$ values were two-sided, and $p \leq 0.05$ was regarded as significant. All analyses were performed with SPSS for Windows, version 12.0.1 (SPSS, Chicago, IL, USA).

The study was approved by the Medical Ethics Reviewing Committee of the Medisch Spectrum Twente Hospital. There were no external sources of funding or study sponsors.

\section{Results}

Over the 26-month prospective observational period the cohort of NSAID users contained 51,903 NSAID users with 10,402 patient years of NSAID exposure. From this cohort, 104 cases were hospitalised with serious NSAID ulcer complications. Because of the geographically isolated position, referral to other hospitals, especially for acute gastrointestinal events, is extremely rare. Therefore, in this population the incidence of hospitalisation due to serious NSAID ulcer complications can be reliably calculated at $1 \%$ per year of NSAID use.

Table 1 shows demographic characteristics and co-morbidities. The typical case is an elderly patient, age at diagnosis $70.4 \pm 16.7$ years (mean \pm SD; range 22 to 98 years), $55.8 \%$ were female. Many patients reported concurrent disease or previous medical events suggesting serious, especially cardiovascular, co-morbidity. This self-reported co-morbidity was supported by the concomitant medication used (Table 2). The 104 cases together used 12 different NSAIDs (Table 2). The duration of NSAID use before the gastrointestinal event varied; the median was 1.13 months (interquartile range 10 days to 12 months). Most patients did not exceed their prescribed maximum daily dose. However, occasional use of more than one NSAID simultaneously was reported by 12 patients (11.5\%).
In most cases (80 patients, 76.9\%), serious NSAID ulcer complication was the reason for presentation and hospitalisation. In the remainder a serious NSAID ulcer complication took place during hospitalisation for another reason. Characteristics of the gastrointestinal events are presented in Table 3. No diagnostic procedure was performed in only six $(5.8 \%)$ patients, because of co-morbidity or advanced age. The mean haemoglobin level at presentation was $6.1 \pm 1.9 \mathrm{mmol} / \mathrm{l}$ (mean $\pm \mathrm{SD}$; range 1.8 to 9.8 ). In those using coumarin, the international normalized ratio (INR) at presentation was $4.87 \pm 1.41$ (mean \pm SD) but the mean haemoglobin level at presentation did not differ from that in patients not taking coumarin, and neither did the number of units of blood administered during hospitalisation.

Mortality due to serious NSAID ulcer complications was high: 11 patients $(10.6 \%)$ died in hospital, and another 4 (3.8\%) died within 3 months of the diagnosis. The incidence of in-hospital mortality due to serious NSAID ulcer complications can be calculated at 21.2 per 100,000 NSAID users.

For 104 cases, 757 controls were selected from the remaining cohort of NSAID users. On receiving the first questionnaire 225 controls responded, of whom 203 were included. On receiving a second questionnaire, a further 123 responded, of whom 81 were included. From the 64 excluded responders, 18 questionnaires were returned by someone other than the selected control, 15 denied taking NSAIDs, 17 refused, 1 had been hospitalised in a psychiatric hospital, 1 was a case who had already been included as such, and for 12 controls relatives informed us that the selected person had died. In the group of 20 randomly selected non-responders who were telephoned, no bias for non-responding was found.

In total 284 controls, frequency matched for age and sex, with NSAID use on the index date were included. Demographic characteristics, co-morbidities and current medication use are summarised in Tables 1 and 2 . The mean age was slightly lower for the controls than for the cases because insufficient numbers of controls could be found for some of the extremely elderly cases.

\section{Statistical results}

In univariate analysis, cases and controls differ significantly with regard to body mass index, smoking habits, marital status, medical history of heart failure, myocardial infarction, stroke and renal insufficiency (Table 1). Significant differences in medication use were found for PPIs, coumarin, low-molecularmass heparin, analgesics, diuretics, angiotensin-convertingenzyme inhibitors, oral glucose-lowering drugs, benzodiazepines and disease-modifying anti-rheumatic drugs (Table 2).

Concomitant use of PPls was significantly higher in the controls than in the cases (cases 13.5\%; controls 27.1\%; $p=$ 
Table 1

\begin{tabular}{|c|c|c|c|c|c|}
\hline Characteristic & Cases $(n=104)$ & Controls $(n=284)$ & OR & $95 \% \mathrm{Cl}$ & $p$ \\
\hline Age at diagnosis (years) & $70.4 \pm 16.7$ & $67.1 \pm 14.3$ & & & \\
\hline Female sex & $58(55.8)$ & $163(57.4)$ & & & \\
\hline Body mass index $\left(\mathrm{kg} / \mathrm{m}^{2}\right)$ & $24.7 \pm 4.7$ & $26.7 \pm 4.6$ & - & - & 0.001 \\
\hline Smoking & $28(26.9)$ & $51(18)$ & 1.96 & $1.15-3.37$ & 0.01 \\
\hline Alcohol (glasses per week) & $9.6 \pm 33.2$ & $6.2 \pm 8.6$ & - & - & 0.12 \\
\hline Coffee (cups per week) & $18.9 \pm 20.6$ & $22.8 \pm 13.8$ & - & - & 0.06 \\
\hline Education low vocational or less & $39(56.5)$ & $176(64.0)$ & 0.73 & $0.43-1.25$ & 0.25 \\
\hline Married & $42(46.7)$ & $166(59.3)$ & 0.60 & $0.37-0.97$ & 0.04 \\
\hline \multicolumn{6}{|l|}{ Medical history } \\
\hline Hypertension & $30(28.8)$ & 95 (33.5) & 0.81 & $0.49-1.32$ & 0.39 \\
\hline Heart failure & $26(25.0)$ & $32(11.3)$ & 2.63 & $1.48-4.67$ & 0.001 \\
\hline COPD & $25(24.0)$ & $57(20.1)$ & 1.26 & $0.74-2.15$ & 0.40 \\
\hline Myocardial infarction & $20(19.2)$ & $32(11.3)$ & 1.88 & $1.02-3.45$ & 0.04 \\
\hline Stroke & $18(17.3)$ & $28(9.9)$ & 1.91 & $1.01-3.63$ & 0.04 \\
\hline Heart rhythm disturbance & $18(17.3)$ & $52(18.3)$ & 0.93 & $0.52-1.69$ & 0.82 \\
\hline Diabetes mellitus & $16(15.4)$ & $33(11.6)$ & 1.38 & $0.73-2.64$ & 0.32 \\
\hline Anaemia & $16(15.4)$ & $32(11.3)$ & 1.43 & $0.75-2.74$ & 0.28 \\
\hline Renal insufficiency & $16(15.4)$ & $15(5.3)$ & 3.26 & $1.55-6.86$ & 0.001 \\
\hline Previous gastrointestinal ulcers & $16(15.4)$ & $33(11.7)$ & 1.37 & $0.72-2.60$ & 0.34 \\
\hline Malignancy & $15(14.4)$ & $26(9.2)$ & 1.67 & $0.85-3.30$ & 0.14 \\
\hline Rheumatoid disease, including OA & $42(40.4)$ & $97(34.2)$ & 1.31 & $0.82-2.07$ & 0.26 \\
\hline
\end{tabular}

Scores are means $\pm \mathrm{SD}$ or number of patients (percentage). OR, unadjusted odds ratio; $\mathrm{Cl}$, confidence interval; COPD, chronic obstructive pulmonary disease; OA, osteoarthritis.

0.005). Use of selective COX-2 inhibitors was comparable (cases $16.4 \%$; controls $17.6 \% ; p=0.77$ ). Use of the preferential COX-2 inhibitor meloxicam differed, but not significantly, and numbers were small (cases 1\%; controls $4.2 \% ; p=0.20$ ).

A full logistic regression model of all significant and other likely causational variables was reduced stepwise to a parsimonious model, finally containing concomitant use of PPIs, low-molecular-mass heparin, acetaminophen, coumarin, and history of heart failure (Table 4). Use of selective COX-2 inhibitors was not associated with a significantly reduced risk for serious NSAID ulcer complications $(p=0.74)$; neither was the use of preferential COX-2 inhibitors $(p=0.22)$. Concomitant use of PPls was associated with a significantly reduced risk for serious NSAID ulcer complications (adjusted odds ratio 0.33; $95 \%$ confidence interval 0.17 to $0.67 ; p=0.002$ ).

In a post hoc subgroup analysis of selective COX-2 inhibitor users, there were no significant differences in concomitant use of low-dose aspirin ( 8 cases $(47 \%) ; 19$ controls $(38 \%) ; p=$ 0.51 ), non-selective NSAIDs (3 cases (18\%); 10 controls
$(20 \%) ; p=0.83)$ or PPls (3 cases $(18 \%) ; 17$ controls $(34 \%)$; $p=0.20)$; neither were there significant differences in concomitant use of coumarin, heparin, steroids or high-dose H2RAs or in ulcer history.

Furthermore, among those taking selective COX-2 inhibitors, cases and controls did not differ significantly with regard to the number of risk factors for NSAID-associated gastropathy, suggesting comparable risk profiles. Similarly, in a post hoc subgroup analysis for those taking either proton-pump inhibitors or high-dose H2RAs, cases and controls again did not differ significantly with regard to the number of risk factors for NSAID-associated gastropathy.

In six patients no diagnostic procedure was performed because of co-morbidity or advanced age. In a post hoc analysis these patients with probable NSAID ulcers were compared with the 98 patients with definite NSAID ulcers. Significant differences between patients with probable or definite NSAID ulcers were age (mean 87.3 and 69.4 years, respectively; $p=0.01$ ), medical history of diabetes mellitus, 
Table 2

NSAIDs and concurrent medication in use at the time of the gastrointestinal event

\begin{tabular}{|c|c|c|c|c|c|}
\hline Medication & Cases $(n=104)$ & Controls $(n=284)$ & OR & $95 \% \mathrm{Cl}$ & $p$ \\
\hline \multicolumn{6}{|l|}{ Non-selective NSAIDs } \\
\hline Indometacin & $3(2.9)$ & $4(1.4)$ & 2.08 & $0.46-9.45$ & 0.39 \\
\hline Naproxen & $10(9.6)$ & $14(4.9)$ & 2.05 & $0.88-4.78$ & 0.09 \\
\hline Diclofenac & $44(42.3)$ & $108(38.0)$ & 1.20 & $0.76-1.89$ & 0.44 \\
\hline Diclofenac-misoprostol & $8(7.7)$ & $19(6.7)$ & 1.16 & $0.49-2.74$ & 0.73 \\
\hline Other NSAIDs & $3(2.9)$ & $8(2.8)$ & 1.03 & $0.27-3.94$ & 1.00 \\
\hline Ibuprofen & $16(15.4)$ & $69(24.3)$ & 0.57 & $0.31-1.03$ & 0.06 \\
\hline High-dose aspirin (>100 mg/day) & $2(1.9)$ & $0(0.0)$ & - & - & 0.07 \\
\hline \multicolumn{6}{|l|}{ Selective NSAIDs } \\
\hline Rofecoxib & $16(15.4)$ & $42(14.8)$ & 1.05 & $0.56-1.96$ & 0.88 \\
\hline Celecoxib & $1(1.0)$ & $8(2.8)$ & 0.34 & $0.04-2.71$ & 0.46 \\
\hline Meloxicam & $1(1.0)$ & $12(4.2)$ & 0.22 & $0.03-1.71$ & 0.20 \\
\hline \multicolumn{6}{|l|}{ Gastroprotective drugs } \\
\hline Proton-pump inhibitors & $14(13.5)$ & $77(27.1)$ & 0.42 & $0.23-0.78$ & 0.005 \\
\hline H2RAs & $4(3.8)$ & $9(3.2)$ & 1.22 & $0.37-4.06$ & 0.74 \\
\hline Misoprostol & $8(7.7)$ & $20(7.0)$ & 1.10 & $0.47-2.58$ & 0.83 \\
\hline \multicolumn{6}{|l|}{ Additional risk factors } \\
\hline High-dose NSAID & $11(10.6)$ & $17(6.0)$ & 1.86 & $0.84-4.11$ & 0.12 \\
\hline More than one NSAID & $12(11.5)$ & $54(19.0)$ & 0.56 & $0.28-1.09$ & 0.08 \\
\hline Low-dose aspirin ( $\leq 100 \mathrm{mg} /$ day) & $32(30.8)$ & $69(24.3)$ & 1.39 & $0.84-2.28$ & 0.20 \\
\hline Clopidogrel/dipyridamole & $5(4.8)$ & $9(3.2)$ & 1.54 & $0.51-4.72$ & 0.54 \\
\hline Coumarin & $14(13.5)$ & $19(6.7)$ & 2.17 & $1.05-4.51$ & 0.04 \\
\hline Low-molecular-mass heparin & $13(12.5)$ & $2(0.7)$ & 20.14 & $4.46-90.94$ & $<0.001$ \\
\hline SSRIs & $6(5.8)$ & $9(3.2)$ & 1.87 & $0.65-5.39$ & 0.24 \\
\hline Corticosteroids & $14(13.5)$ & $32(11.3)$ & 1.23 & $0.63-2.40$ & 0.55 \\
\hline \multicolumn{6}{|l|}{ Analgesics } \\
\hline Acetaminophen & $45(43.3)$ & $54(19.0)$ & 3.25 & $1.99-5.29$ & $<0.001$ \\
\hline Tramadol & $12(11.5)$ & $6(2.1)$ & 6.04 & $2.21-16.56$ & $<0.001$ \\
\hline Morphine & $6(5.8)$ & $2(0.7)$ & 8.63 & $1.71-43.48$ & 0.006 \\
\hline \multicolumn{6}{|l|}{ Cardiovascular drugs } \\
\hline Diuretics & 34 (32.7) & $57(20.1)$ & 1.93 & $1.17-3.20$ & 0.009 \\
\hline ACE inhibitors & $24(23.1)$ & $32(11.3)$ & 2.36 & $1.32-4.25$ & 0.003 \\
\hline Digoxin & $8(7.8)$ & $11(3.9)$ & 2.09 & $0.82-5.35$ & 0.12 \\
\hline Beta-blockers & $22(21.2)$ & $64(22.5)$ & 0.92 & $0.53-1.59$ & 0.77 \\
\hline Nitrates & $8(7.7)$ & $26(9.2)$ & 0.83 & $0.36-1.89$ & 0.65 \\
\hline Calcium-channel blockers & $10(9.6)$ & $35(12.3)$ & 0.76 & $0.36-1.59$ & 0.46 \\
\hline Lipid-lowering drugs & $9(8.7)$ & $38(13.4)$ & 0.61 & $0.29-1.32$ & 0.21 \\
\hline Oral glucose-lowering drugs & $12(11.5)$ & $15(5.3)$ & 2.34 & $1.06-5.18$ & 0.03 \\
\hline Benzodiazepines & $34(32.7)$ & $65(22.9)$ & 1.64 & $0.99-2.68$ & 0.05 \\
\hline Inhalator therapy & $22(21.2)$ & $56(19.7)$ & 1.09 & $0.63-1.90$ & 0.76 \\
\hline DMARDs & $14(13.5)$ & $20(7.0)$ & 2.05 & $0.99-4.23$ & 0.05 \\
\hline
\end{tabular}

Scores are number of patients (percentage). NSAIDs, non-steroidal anti-inflammatory drugs; OR, unadjusted odds ratio; $\mathrm{Cl}$, confidence interval; H2RAs, histamine-2 receptor antagonists; SSRIs, selective serotonin re-uptake inhibitors; ACE, angiotensin-converting enzyme; DMARDs, disease-modifying anti-rheumatic drugs. High-dose NSAID is more than the daily defined dose. 
Table 3

Characteristics of the gastrointestinal event attributable to use of non-steroidal anti-inflammatory drugs

\begin{tabular}{ll}
\hline Characteristic & Number (percentage) \\
\hline Clinical presentation & $65(62.5)$ \\
Melaena & $28(26.9)$ \\
Haematemesis & $12(11.5)$ \\
Perforation & $21(20.2)$ \\
Stomach pain & $16(15.4)$ \\
Collapse & $57(54.8)$ \\
No previous stomach & \\
complaints & \\
Ulcer location & $53(51.0)$ \\
Gastric & $34(32.7)$ \\
Duodenal & $11(10.6)$ \\
Both gastric and duodenal & $6(5.7)$ \\
No diagnostic procedure & $14(13.5)$ \\
performed & \\
Ulcer perforation & $21(20.2)$ \\
Helicobacter pylori & $45(43.3)$ \\
Positive & $38(36.5)$ \\
Negative & \\
Not tested & \\
\hline
\end{tabular}

The total number of patients was 104 .

chronic obstructive pulmonary disease and in-hospital mortality $(66.7 \%$ and $7.1 \%$, respectively; $p=0.001)$. Excluding these patients with probable NSAID ulcers from the cases did not significantly change the results of the univariate or multivariate analyses.

Table 4

Multivariate analysis of significant variables and other likely causational variables for serious NSAID ulcer complications

\begin{tabular}{llll}
\hline Predictor & Adjusted OR & $95 \% \mathrm{Cl}$ & $p$ \\
\hline $\begin{array}{l}\text { Proton-pump } \\
\text { inhibitors }\end{array}$ & 0.33 & $0.17-0.67$ & 0.002 \\
Coumarin & 2.09 & $0.93-4.70$ & 0.075 \\
Heart failure & 2.44 & $1.28-4.66$ & 0.007 \\
$\begin{array}{l}\text { Acetaminophen } \\
\text { Low-molecular- }\end{array}$ & 2.80 & $1.64-4.79$ & $<0.001$ \\
mass heparin & & $3.71-80.95$ & $<0.001$ \\
\hline
\end{tabular}

Serious non-steroidal anti-inflammatory drug (NSAID) ulcer complication was the dependent variable. Only variables from the final parsimonious model are shown. OR, odds ratio; $\mathrm{Cl}$, confidence interval.
Table 5

Multivariate analysis after exclusion of patients with inhospital NSAID ulcer complications

\begin{tabular}{llll}
\hline Predictor & Adjusted OR & $95 \% \mathrm{Cl}$ & $p$ \\
\hline Proton-pump inhibitors & 0.31 & $0.15-0.66$ & 0.002 \\
Coumarin & 2.38 & $1.03-5.48$ & 0.04 \\
Heart failure & 2.10 & $1.04-4.21$ & 0.04 \\
Acetaminophen & 2.47 & $1.39-4.39$ & 0.002 \\
Low-molecular-mass heparin & 6.06 & $0.91-40.60$ & 0.06 \\
\hline $\begin{array}{l}\text { Serious non-steroidal anti-inflammatory drug (NSAID) ulcer } \\
\text { complication was the dependent variable. Only variables from the } \\
\text { final parsimonious model are shown. OR, odds ratio; Cl, confidence } \\
\text { interval. }\end{array}$
\end{tabular}

In 24 patients, serious NSAID ulcer complications occurred in hospital. These patients were compared with the 80 patients who presented with NSAID ulcer complications. Significant differences between in-hospital or presenting patients were sex $(37.5 \%$ and $61.3 \%$ female, respectively; $p=0.04)$, ulcer history $(29.2 \%$ and $11.3 \%$, respectively; $p=0.03)$, medical history of a malignancy, diabetes mellitus, use of oral glucoselowering drugs and use of low-molecular-mass heparin $(45.5 \%$ and $3.8 \%$, respectively; $p<0.001)$. Exclusion of these in-hospital patients from the cases resulted in a significant change in the univariate analyses for use of oral glucose-lowering drugs (cases $6.3 \%$; controls $5.3 \% ; p=0.74$ ) and for use of low molecular mass heparin (cases $3.8 \%$; controls $0.7 \% ; p$ $=0.04)$. The results of the multivariate analysis also changed (Table 5).

\section{Discussion}

In this nested case-control study, the concomitant use of proton-pump inhibitors was associated with a two-thirds reduction in the risk for serious NSAID ulcer complications. The efficacy of PPIs in the primary prevention of NSAID-associated gastropathy has so far only been proven for subjective symptoms and surrogate endpoints, such as dyspepsia and endoscopic ulcers, and in the secondary prevention of serious NSAID ulcer complications, PPls do not seem to prevent recurrence $[12,14,15]$. Our data suggest that PPls may be effective in the primary prevention of clinically relevant bleeding and perforated NSAID ulcers, confirming other recent observational studies [16-18]. However, randomised controlled trials powered on these hard endpoints need to be conducted to prove efficacy.

It is noteworthy that in this study the use of selective COX-2 inhibitors was not associated with protection for serious NSAID ulcer complications. Lack of protection from selective COX-2 inhibitors could not be explained by confounders such as concomitant use of aspirin, coumarin, heparin or steroids or by ulcer history. Previous studies demonstrating the efficacy of selective COX-2 inhibitors in the primary prevention of NSAID ulcer complications largely excluded high-risk patients, 
whereas in high-risk patients selective COX-2 inhibitors may fail to prevent the recurrence of NSAID ulcer bleeding $[12,14,15]$. Although neither selective COX-2 inhibitors nor concomitant PPls seem to be entirely effective in preventing the recurrence of ulcer complications, our data suggest that PPls may be superior to selective COX-2 inhibitors in the primary prevention of NSAID ulcer complications.

Cases used coumarin more often than controls (adjusted odds ratio 2.09; 95\% confidence interval 0.93 to $4.70 ; p=0.075$ ). Furthermore, in those cases using coumarin, the mean INR at presentation was $4.87 \pm 1.41$ (mean \pm SD) and one-third (5 patients) had an INR greater than 6.5. Although no INR was measured in the controls, it is possible that this elevated INR contributed to these patients developing serious NSAID ulcer bleeding.

Cases used low-molecular-mass heparin significantly more often than controls (adjusted odds ratio 17.33; 95\% confidence interval 3.71 to $80.95 ; p<0.001$ ). In addition, cases used acetaminophen significantly more often than controls (adjusted odds ratio 2.80; 95\% confidence interval 1.64 to $4.79 ; p<0.001)$. It is possible that these differences reflect inhospital treatment protocols rather than a true elevated risk for serious NSAID ulcer complications. However, an increased risk for NSAID ulcers with concomitant high-dose acetaminophen has been reported previously [13]. Exclusion of patients with in-hospital NSAID ulcer complications truncated the odds ratio for low-molecular-mass heparin (adjusted odds ratio 6.06 ; $95 \%$ confidence interval 0.91 to $40.60 ; p=0.06$; Table 5).

Cases reported a history of heart failure significantly more often than controls (adjusted odds ratio $2.44 ; 95 \%$ confidence interval 1.28 to $4.66 ; p=0.007$ ). The association between heart failure and risk for NSAID-associated gastropathy has previously been demonstrated, but a credible causational mechanism remains to be identified [19].

One of the strengths of this study is that it reflects daily clinical practice. The large randomised controlled clinical trials that demonstrated the efficacy and safety of selective COX-2 inhibitors were conducted in relatively young, healthy subjects. Our study suggests that these may not be the patients who are especially at risk for serious NSAID ulcer complications and confirms another recently conducted large nested case-control study that also found no evidence for enhanced gastrointestinal safety with selective COX-2 inhibitors [20]. Another strength of our study lies in the robustness of the data. Gastrointestinal events in cases and controls were verified, as were data on actual medication used. Other groups have studied populations of up to several thousand patients, but associations were derived by coupling databases and the validity of the data was not always verified $[21,22]$.
The local infrastructure makes it unlikely that many cases were missed. However, one weakness of this study is that underestimation of the number of events might still have occurred. Another weakness of this study, as in any case-control study, is the possibility of selection bias. Although we have controlled for all known possible confounders, selection by indication or an unknown confounding mechanism cannot be excluded with certainty.

\section{Conclusion}

Serious NSAID ulcer complications have a significant mortality rate: $10.6 \%$ die in hospital and $14.4 \%$ within 3 months of the event. At risk are especially elderly patients with cardiovascular co-morbidity. In daily clinical practice, the concomitant use of PPIs is associated with a two-thirds reduction in the risk for serious NSAID ulcer complications.

\section{Competing interests}

The authors declare that they have no competing interests.

\section{Authors' contributions}

All authors contributed significantly to writing the article. HEV and RWF also contributed to the selection and inclusion of cases and controls. JvdP also contributed to the statistical analysis of the data. All authors read and approved the final manuscript.

\section{Acknowledgements}

The authors wish to thank all participating community-based pharmacies in Enschede. The authors also wish to thank all participating physicians, especially those at the departments of Gastroenterology, Surgery and Internal Medicine, the nurses and physician assistants at the Department of Gastroenterology, the research nurses at the Department of Rheumatology and Clinical Immunology, and the coders and archivists of the Medisch Spectrum Twente Hospital in Enschede, The Netherlands.

\section{References}

1. Elliott SL, Ferris RJ, Giraud AS, Cook GA, Skeljo MV, Yeomans ND: Indomethacin damage to rat gastric mucosa is markedly dependent on luminal pH. Clin Exp Pharmacol Physiol 1996, 23:432-434.

2. Rostom A, Wells G, Tugwell P, Welch V, Dube C, McGowan J: The prevention of chronic NSAID induced upper gastrointestinal toxicity: a Cochrane collaboration meta-analysis of randomised controlled trials. J Rheumato/ 2000, 27:2203-2214.

3. Silverstein FE, Graham DY, Senior JR, Davies HW, Struthers BJ, Bittman RM, Geis GS: Misoprostol reduces serious gastrointestinal complications in patients with rheumatoid arthritis receiving nonsteroidal anti-inflammatory drugs. $A$ randomized, double-blind, placebo-controlled trial. Ann Int Med 1995, 123:241-249.

4. Hawkey CJ, Karrasch JA, Szczepanski L, Walker DG, Barkun A, Swannell AJ, Yeomans ND: Omeprazole compared with misoprostol for ulcers associated with nonsteroidal anti-inflammatory drugs. N Engl J Med 1998, 338:727-734.

5. Yeomans ND, Tulassay Z, Juhasz L, Racz I, Howard JM, van Rensburg CJ, Swannell AJ, Hawkey CJ, for the ASTRONAUT study group: A comparison of omeprazole with ranitidine for ulcers associated with nonsteroidal anti-inflammatory drugs. $N$ Engl J Med 1998, 338:719-726.

6. Hawkey CJ: COX-2 inhibitors. Lancet 1999, 353:307-314. 
7. FitzGerald GA, Patrono C: The coxibs, selective inhibitors of cyclooxygenase-2. N Engl J Med 2001, 345:433-442.

8. Bombardier C, Laine L, Reicin A, Shapiro D, Burgos-Vargas R, Davis B, Day R, Ferraz MB, Hawkey CJ, Hochberg MC, Kvein TK, Schnitzer TJ: Comparison of upper gastrointestinal toxicity of rofecoxib and naproxen in patients with rheumatoid arthritis. VIGOR Study Group. N Engl J Med 2000, 343:1520-1528.

9. Silverstein FE, Faich G, Goldstein JL, Simons LS, Pincus T, Whelton A, Makuch R, Eisen G, Agrawal NM, Stenson WF, et al.: Gastrointestinal toxicity with celecoxib vs nonsteroidal antiinflammatory drugs for osteoarthritis and rheumatoid arthritis: the CLASS study: a randomized controlled trial. Celecoxib Long-term Arthritis Safety Study. JAMA 2000, 284:1247-1255.

10. Hunt RH, Harper S, Watson DJ, Yu C, Quan H, Lee M, Evans JK, Oxenius B: The gastrointestinal safety of the COX-2 selective inhibitor etoricoxib assessed by both endoscopy and analysis of upper gastrointestinal events. Am J Gastroenterol 2003, 98:1725-1733.

11. Farkouh ME, Kirshner H, Harrington RA, Ruland S, Verheugt FW, Schnitzer TJ, Burmester GR, Mysler E, Hochberg MC, Doherty M, et al:: Comparison of lumiracoxib with naproxen and ibuprofen in the Therapeutic Arthritis Research and Gastrointestinal Event Trial (TARGET), cardiovascular outcomes: randomized controlled trial. Lancet 2004, 364:675-84.

12. Chan FK, Hung LC, Suen BY, Wu JC, Lee KC, Leung VK, Hui AJ, To KF, Leung WK, Wong VW, et al.: Celecoxib versus diclofenac and omeprazole in reducing the risk of recurrent ulcer bleeding in patients with arthritis. $N$ Engl J Med 2002, 347:2104-2110.

13. Garcia Rodrigues LA, Hernandez-Diaz S: The risk of upper gastrointestinal complications associated with nonsteroidal antiinflammatory drugs, glucocorticoids, acetaminophen, and combinations of these agents. Arthritis Res 2001, 3:98-101.

14. Chan FK, Hung LC, Suen BY, Wong VW, Hui AJ, Wu JC, Leung WK, Lee YT, To KF, Chung SC, Sung JJ: Celecoxib versus diclofenac plus omeprazole in high-risk arthritis patients: results of a randomized double-blind trial. Gastroenterology 2004, 127:1038-1043.

15. Lai KC, Chu KM, Hui WM, Wong BC, Hu WH, Wong WM, Chan AO, Wong J, Lam SK: Celecoxib compared with lansoprazole and naproxen to prevent gastrointestinal ulcer complications. Am J Med 2005, 118:1271-1278.

16. Lanas A, Garcia-Rodriguez LA, Arroyo MT, Bujanda L, Gomollon F, Forne M, Aleman S, Nicolas D, Feu F, Gonzalez-Perez A, et al:: Effect of antisecretory drugs and nitrates on the risk of ulcer bleeding associated with nonsteroidal anti-inflammatory drugs, antiplatelet agents, and anticoagulants. $A m \mathrm{~J}$ Gastroenterol 2007, 102:507-515.

17. Lanas A, Garcia-Rodriguez LA, Arroyo MT, Gomollon F, Feu F, Gonzalez-Perez A, Zapata E, Bastida G, Rodrigo L, Santolaria S, et al.: Risk of upper gastrointestinal ulcer bleeding associated with selective cyclo-oxygenase-2 inhibitors, traditional nonaspirin non-steroidal anti-inflammatory drugs, aspirin and combinations. Gut 2006, 55:1731-1738.

18. Garcia Rodriguez LA, Barreales Tolosa L: Risk of upper gastrointestinal complications among users of traditional NSAIDs and COXIBs in the general population. Gastroenterology 2007, 132:498-506

19. Weil J, Langman MJ, Wainwright $P$, Lawson $D H$, Rawlins $M$, Logan RF, Brown TP, Vessey MP, Murphy M, Colin-Jones DG: Peptic ulcer bleeding: accessory risk factors and interactions with non-steroidal anti-inflammatory drugs. Gut 2000, 46:27-31.

20. Hippisley-Cox J, Coupland C, Logan R: Risk of adverse gastrointestinal outcomes in patients taking cyclo-oxygenase-2 inhibitors or conventional non-steroidal anti-inflammatory drugs: population based nested case-control analysis. BMJ 2005, 331:1310-1316.

21. Singh G, Rosen Ramey D: NSAID-induced gastrointestinal complications: the ARAMIS perspective - 1997. J Rheumatol Suppl 1998, 51():8-16.

22. Hernandez-Diaz S, Garcia Rodrigues LA: Association between nonsteroidal anti-inflammatory drugs and upper gastrointestinal tract bleeding/perforation. An overview of epidemiologic studies published in the 1990s. Arch Intern Med 2000, 160:2093-2099. 